\title{
Economic burden and catastrophic cost among people living with type 2 diabetes mellitus attending a tertiary health institution in south-east zone, Nigeria
}

Ijeoma L. Okoronkwo' ${ }^{1}$, Jessie N. Ekpemiro ${ }^{2 *}$, Edna U. Okwor ${ }^{2}$, Pat U. Okpala ${ }^{3}$ and Florence O. Adeyemo ${ }^{4}$

\begin{abstract}
Background: Diabetes mellitus (DM) is a life-long illness that affects the quality of life, requiring close monitoring and control. Type $2 \mathrm{DM}$ is preventable and controllable but increasing cost of care could hinder access to quality care because of inability to pay leading to high morbidity, mortality and productivity losses. The people living with diabetes mellitus (PLWD) in Nigeria have high risk for high economic burden and catastrophic expenditure not only because they make frequent visits to the health facilities, report late with complications but also pay out of pocket at the point of accessing care. The aim of this study was to assess the magnitude of economic burden borne and catastrophic costs incurred by PLWD in Nigeria.
\end{abstract}

Methods: Cross-sectional descriptive survey design was used to study a sample of 308 type2 PLWD managed at a tertiary health institution, South east Nigeria using semi-structured, prevalidated questionnaire. Data collection period was 2 months.

Results: The major findings were economic burden of type 2 DM of N56,245 (\$356). Catastrophic direct cost was $45 \%$ at $30 \%$ threshold (the determinant level for catastrophic spending set). All socio-economic status (SES) groups suffered catastrophic expenditure but the poorest quartile had the highest incidence.

Conclusions: Economic burden of DM was high for PLWD who also suffered high catastrophic costs due to the impact of out of pocket payment. PLWD need financial protection especially for the poorest since they buy from the same market and incur same costs. Policy decision making to assist the PLWD cope with cost of care is needful in Nigeria and nations with related problems.

Keywords: Economic burden, Catastrophic cost, Type2 diabetes mellitus (DM), Socioeconomic status

\section{Background}

Diabetes mellitus (DM) is a group of chronic medical conditions in which the body's metabolism is deranged either due to absence or insufficient production of insulin or the body does not properly respond to insulin; producing a persistent hyperglycaemic state [1]. The persistent hyperglycaemia and associated complications demand

*Correspondence: ekpemiroj@gmail.com

2 Federal Medical Centre Umuahia, Umuahia, Abia State, Nigeria

Full list of author information is available at the end of the article intensive care and frequent visits to health facilities thus increasing the cost of care.

DM affects quality of life, requires close monitoring and control. Diabetes mellitus is a growing "epidemic and pandemic" [1]. Globally, about 285 million people had DM in 2010, projected to double by 2030 [2]. Nigeria's diabetes prevalence of 20.8 million ( $7 \%$ of population) [3, $4]$ and her ranking largest in African regional prevalence in 2011 is a great concern [5].

Diabetes is the third cause of death from disease and complications [6], second killer non communicable disease [7], has five fold risks of cardiovascular diseases 
and three fold of stroke [6]. PLWD in Nigeria have risk for high economic burden and catastrophic expenditure because the three conditions that predict financial catastrophe; healthcare cost paid out of pocket, individuals' inability to pay and absence of prepayment mechanisms to pool financial risks [8] are prevalent in Nigeria.

Economic burden in this study means direct cost of care. Catastrophic Healthcare expenditure is very high healthcare spending in relation to one's income beyond which an individual begins to sacrifice consumption of basic needs and use payment coping mechanisms (interium measures to meet up with payment but in the long run increase the total cost). WHO proposed $40 \%$ and above of non-subsistence income consumption (nonfood consumption expenditure); that is income available after basic needs have been met but countries could set their thresholds based on their peculiarities [7]. Non-food consumption expenditure is used as proxy to income because it is sensitive; availability of cash and income information are not easily and accurately declared in African countries $[9,10]$.

Previous studies put catastrophic level at 5-40 \% [712]. In Nigeria private funding is more than $90 \%$ [9]. More than $70 \%$ of the population live below $\$ 1$ a day [12, 13] and prepayment mechanism for pooling risk is lacking [9]. Economic impact of healthcare expenditure on individuals challenged with illness especially where prepayment system is absent is a growing concern [14]. Every year more than 150 million individuals in the world face financial catastrophe and more than 100 million individuals are pushed into poverty as a direct result of paying for health care $[7,8,14]$. This could be worse for patients living with Diabetes Mellitus in Nigeria, who receive frequent treatment paid out of pocket coupled with increasing healthcare costs. The burden borne also depends on the amount and level of care received [15], purchasing power of individuals and social insurance policies of that nation [16]. One is bothered that despite the fact that UN in 2011 raised the status of non-communicable diseases (NCDs) to that of HIV/AIDS, TB and Malaria because of their economic and health importance [7, 17], there is neither support, nor financial risk protection (exemption) for DM which is presently assuming an epidemic proportion $[2,5]$ and presence of development partners and non-governmental organisation (NGOs) have not been felt in DM care [17]. The economic importance, complications and death tolls are compelling national governments to pay more attention to the impacts of DM $[7,17$, 18 ] especially with its late diagnosis in Nigeria and some other Sub Saharan African countries [19-21].

Evidenced-based data is needed to move DM into the health policy agenda of these countries for targeted intervention. Unfortunately, there is paucity of data on the magnitude of the economic burden borne and catastrophic costs incurred by the diabetic Patients in Nigeria. The specific objectives of this study assessed;

1. The direct cost borne by PLWD type 2 in treating diabetes.

2. The catastrophic costs incurred by different SES groups of PLWD attending a tertiary health institution in South-East Nigeria with a view of reducing the economic burden through appropriate decision making.

\section{Methods}

\section{Study design and setting}

A cross sectional descriptive survey design was used for this study. This was considered appropriate because the 'cost-of-illness estimate' is a descriptive economic method often used to estimate cost of a particular disease [22].

The study was done in a Sate, South East Nigeria, covering an area of $5834 \mathrm{sq} \mathrm{km}, 5.8 \%$ of total land mass of Nigeria and has a population of 2,833,999 [23]. It is both a residential and commercial city and has both urban and rural dwellers. The area is made up of civil servants, traders and farmers. The hospital serves both self and health system referred patients. This study was approved by the Ethics Research Committee of Federal Medical Centre (FMC) Umuahia (FMC/QEH/G.596/VOL.4/006).

\section{Study participants}

Population for this study were all type2 DM patients receiving treatment for diabetes mellitus in the institution. An average of 1363 type 2 PLWD received care from the centre in the last 1 year, (diagnostic index 2009-2011 of the Health Records Department) 139 were admitted and managed as in patients while 1224 PLWD were attended to as out-patients (target population). Eligibility criteria were age between 31 and 65 years, receiving treatment in the centre for the past 1 year (July 2011-June 2012) and within the 2 months data collection period, should be actively involved in the management of the condition, well informed about the cost of care (have adequate knowledge of cost of care by self report) and willing to participate in the study.

\section{Study size}

The minimum sample size of 308 was calculated using the formula for estimating a single finite proportion $\mathrm{n}=\mathrm{Z}^{2} \times \mathrm{p}(1-\mathrm{p}) / \mathrm{d}^{2}$ (Isangedihi et al. 2004) from a target population of 1224 physician diagnosed type 2 diabetes mellitus. Due to lack of information on the proportion of type $2 \mathrm{DM}$ in economic burden studies, $50 \%$ or 0.5 was chosen as p giving an initial sample size of 384 . 
2nd stage: In order to obtain the finite population correction for proportion for a small population the formula $\mathrm{n}=\mathrm{n}_{0} / 1+\left(\mathrm{n}_{0}-1\right) / \mathrm{N}$ was used to get 293.13.

3rd stage: Since data were to be collected directly from the respondents, it was anticipated that as many as $5 \%$ might withdraw from the study prior to its completion through possible refusal to continue with the study. Thus the formula $\mathrm{q}=\mathrm{n} / 1-\mathrm{f}$ where $\mathrm{q}$ is the adjustment factor and $\mathrm{f}$ is the estimated non response rate was used [ANGEL (n.d.).STAT 509] was used. Therefore the final sample size was 308. However 292 copies of the questionnaire were found to be correctly and completely filled while 16 proposed participants declined.

The Clinics' appointment registers were used to form a sampling frame. The sampling interval for sample recruitment was 3.97. Therefore every 4th person was systematically recruited on each clinic day till 308 respondents that met the eligibility criteria were selected.

\section{Variables}

The variables of interest were: economic burden, catastrophic diabetic cost, and socioeconomic status. Economic burden was measured by the unit cost of all type 2 diabetes out patient services received. Catastrophic diabetic cost was measured by non food consumption expenditure of the respondents (income) plus the direct cost of diabetes. Socioeconomic status groups was measured by number of household items owned by respondents.

\section{Data collection}

A pretested researcher administered semi-structured questionnaire was used. It comprised of three sections with sixteen questions to elicit responses from respondents based on study objectives. Section A was on demographic characteristics of respondents; section $\mathrm{B}$, on economic burden and section $\mathrm{C}$, on socio economic status and catastrophic cost while the coefficient alpha (Cronbach's alpha) method was used to calculate the internal consistency reliability of the instrument using 30 PLWD from a peripheral clinic. The co-efficient of reliability obtained by sections were $0.40,0.80$ and 0.75 (sections $\mathrm{A}-\mathrm{C}$ ), respectively. The low reliability co-efficient of 0.4 from section A (demographic characteristics of respondents) was related to the heterogeneity created by the string (gender). The study focus was not on the influence of demographic characteristics on economic burden nor catastrophic expenditure, therefore it was considered inconsequential to the study outcome. However, the instrument was late updated with outcome of the pretested questionnaire. Informed consents of the patients were obtained and assurance of confidentiality of all information received given. Participants were informed that participation is voluntary. The researchers and the three research assistants trained on the purpose of the study and how to administer the instrument collected the data until the 308 respondents who met the inclusion criteria were recruited. The instrument was administered within the hours of 8 am and $1 \mathrm{pm}$ while the patients awaited their fasting plasma glucose results and to see their physicians to avoid disruption of daily clinic activities and ensure good attention from patients.

\section{Data analysis}

The data gathered were collated, cleaned, coded, grouped and subjected to descriptive statistics on Statistical Package for Social Sciences (SPSS) version 16.0 and presented in percentages, frequencies, means and standard deviations.

Data on personal profile were analyzed using frequencies, percentages means and standard deviations. The economic burden (direct cost) of DM was articulated using bottom-up approach to aggregate the mean cost of units of services received through whole encounter with the health facilities using 1 month recall period. The socio-economic status was determined using principle component analysis (PCA) in STATA Software based on ownership of household assets. The assets were ownership of motorcar, motorcycle, radio, refrigerator, television set and bicycle, electric fan and so on. PCA was used to generate an assets based socio-economic index (grouping all the numerous household items into one whole number) which was then used to divide the respondents into four socioeconomic quartiles (q1-q4) of poorest, poorer, poor and least poor. The first component of the PCA was used to derive weights (eigenvectors) for the SES index. The highest weight was assigned to refrigerator 0.601 , followed by personal computer 0.57 and so on as in Table 1 . Measure of inequality was the ratio of the mean non-food expenditure of the poorest SES group over that of the least poor. Catastrophic DM cost was determined as a proportion of direct DM cost and non-food expenditure at fixed threshold of $30 \%$ for all SES and 40 and $10 \%$ variable threshold for the least poor and the poorest, respectively. The association between catastrophic DM costs and socio-economic status was assessed using proportions.

\section{Results}

Of the 308 questionnaires administered, 292 which were properly completed (a return rate of $95 \%$ ) were analysed and the data presented in Tables. The 16 who declined participation reported that they found the asset based questions sensitive. From Table 1, the mean age of respondents was 54 years, with $(67 \%)$ within $50-65$ years age group. (53\%) of respondents were females. $79 \%$ 
Table 1 Demographic characteristics of respondents $\mathbf{n}=\mathbf{2 9 2}$

\begin{tabular}{|c|c|c|}
\hline & Frequency & $\%$ \\
\hline \multicolumn{3}{|l|}{ Age group (in years) } \\
\hline $30-40$ & 40 & 14 \\
\hline $41-50$ & 56 & 19 \\
\hline $50-65$ & 196 & 67 \\
\hline Total & 292 & 100 \\
\hline Mean age & 54 & \\
\hline \multicolumn{3}{|l|}{ Gender } \\
\hline Male & 136 & 46 \\
\hline Female & 156 & 54 \\
\hline Total & 292 & 100 \\
\hline \multicolumn{3}{|l|}{ Marital status } \\
\hline Married & 231 & 79 \\
\hline Single & 16 & 6 \\
\hline Divorced & 1 & 0.3 \\
\hline Widow & 41 & 14 \\
\hline Widower & 3 & 1 \\
\hline Total & 292 & 100 \\
\hline \multicolumn{3}{|l|}{ Highest educational attainment } \\
\hline No formal education & 28 & 10 \\
\hline Primary education & 76 & 26 \\
\hline Junior secondary & 5 & 2 \\
\hline Senior secondary & 63 & 22 \\
\hline University/college/polytechnic & 119 & 41 \\
\hline Post graduate & 1 & 3 \\
\hline Total & 292 & 100 \\
\hline \multicolumn{3}{|l|}{ Employment status } \\
\hline Unemployed & 10 & 3 \\
\hline Govt. employed & 73 & 25 \\
\hline Private employed & 16 & 6 \\
\hline Self employed & 92 & 32 \\
\hline Retired & 57 & 20 \\
\hline Farming & 33 & 11 \\
\hline Housewife & 11 & 4 \\
\hline Total & 292 & 100 \\
\hline
\end{tabular}

were married. $41 \%$ had university/college/polytechnic education while 28 (10\%) had no formal education. 73 (25\%) of the respondents were employed by the government, 16 (6\%) were in private sector employment, 57 (20\%) had retired, 92 (32\%) were self-employed, 10 (3\%) unemployed, 33 (11\%) were farmers while $11(4 \%)$ were housewives.

Table 2 shows the cost units on which direct cost was calculated. Cost of DM diet ranked highest N28,524 (\$181) followed distantly by drug and investigations; N7701 (\$49) and N4236 (\$27), respectively. The monthly
Table 2 Direct cost of DM per month reflecting unit costs $n=292 \mathrm{~N}$ (US\$)

\begin{tabular}{lcl}
\hline Cost units & Mean $(\overline{\mathbf{X}})$ & $\begin{array}{l}\text { Standard } \\
\text { deviation (SD) }\end{array}$ \\
\hline Folder & $20(0.13)$ & $25(0.16)$ \\
Drugs & $7702(49)$ & $6922(44)$ \\
Lab. tests/investigations & $4932(31)$ & $5628(36)$ \\
Consultation fees & $257(2)$ & $499(3)$ \\
Insurance premium/co-payment & $887(6)$ & $3351(21)$ \\
Transport & $999(6.3)$ & $3073(19)$ \\
Diabetic diet & $28,524(181)$ & $16,070(102)$ \\
Self-monitoring of glucose & $3128(20)$ & $5984(38)$ \\
Insulin syringe/disposables & $959(6.1)$ & $2575(16)$ \\
Extra house helper & $1884(1.2)$ & $4749(30)$ \\
Physiotherapy & $253(2)$ & $2872(18)$ \\
Dressings & $399(3)$ & $1925(12)$ \\
Cost incurred elsewhere same & $3409(22)$ & $12,797(81)$ \\
$\quad$ period on DM & & \\
Cost of DM related diseases & $2894(18)$ & $5934(38)$ \\
Total & $56,245(356)$ & $28,907(183)$ \\
\hline
\end{tabular}

direct cost of DM was N56,245 (\$356). In Table 3, the respondents were categorized into four socioeconomic status groups using (PCA) on STATA software. The first component of the PCA was used to assign weights and assets based index developed using household assets owned by the respondents. The highest weight was assigned to refrigerator (.601) followed by personal computer (.57) and so on as in Table 3. The socioeconomic status quartiles were named as poorest (q1), poorer (q2) poor (q3) and the least poor (q4).

Table 4 showed the mean respondents' expenditure on food and non-food per month. DM costs as a proportion of non-food expenditure (N256,000) (\$1620) was $20 \%$. Catastrophic expenditure was $45 \%$ at $30 \%$ threshold. In Table 5, the mean non-food expenditure was N256,000 (\$1620). The poorest (q1) spent N24,617 (\$156) and the least poor group expended N120,228 (\$761) on non-food. The ratio of $\mathrm{q} 1 / \mathrm{q} 4$ was $1: 4.9$. The non-food expenditure of the least poor was 4.9 times that of the poorest group. At $30 \%$ fixed threshold, the catastrophic levels were 78, 47,52 and $39 \%$ (q1-q4), respectively while at variable threshold of 10 and $40 \%$ threshold (q1 and q4), the costs were 86 and $17 \%$, respectively. Majority that suffered catastrophic expenditure at $30 \%$ threshold belong to the poorest SES group 58 (78 \%) followed by the poor (q3) 38 (52\%). All SES groups experienced catastrophic expenditure at $10 \%$ threshold but the poorest was worst affected $64(86 \%)$ followed by the poorer poor 56 (79\%). Direct cost as a proportion of non-food consumption was $20 \%$. 
Table 3 Categorization of respondents into socioeconomic status on assets based index $\mathbf{n}=\mathbf{2 9 2}$

\begin{tabular}{lccc}
\hline Household item & Weight & Yes & No \\
\hline Radio & .53 & $284(97 \%)$ & $8(3 \%)$ \\
Television & .24 & $277(95 \%)$ & $262(90 \%)$ \\
Air conditioner & .48 & $29(10 \%)$ & $273(94 \%)$ \\
Bicycle & .003 & $19(6 \%)$ & $267(91 \%)$ \\
Motorcycle & -.012 & $25(9 \%)$ & $186(64 \%)$ \\
Car & .34 & $106(36 \%)$ & $123(42 \%)$ \\
Refrigerator & .601 & $169(58 \%)$ & $110(38 \%)$ \\
Power generating set & .29 & $182(62 \%)$ & $217(74 \%)$ \\
Gas cooker & .07 & $75(26 \%)$ & $38(13 \%)$ \\
Electric fan & -.033 & $254(87 \%)$ & $252(87 \%)$ \\
Microwave oven & .18 & $39(13 \%)$ & $276(95 \%)$ \\
Washing machine & .30 & $14(5 \%)$ & $257(89 \%)$ \\
Personal computer & .57 & $32(11 \%)$ & Percentage \\
\hline Socioeconomic status & Quartiles & Frequency & 24.7 \\
\hline Least poor & Q4 & 72 & 25 \\
Poor & Q3 & 73 & 25 \\
Poorer poor & Q2 & 73 & 25.3 \\
Poorest & Q1 & 74 & 100 \\
Total & & 292 & \\
\hline
\end{tabular}

Table 4 Respondents' monthly expenditure and mean catastrophic DM cost at $30 \%$ threshold N(US\$)

\begin{tabular}{lll}
\hline Respondents' expenditure & Mean $(\overline{\mathbf{X}})$ & Standard deviation (SD) \\
\hline Food purchased & $31,800(201)$ & $39,629(251)$ \\
Food produced & $9924(63)$ & $15,233(96)$ \\
Clothing & $28,300(179)$ & $33,884(215)$ \\
Rent & $24,400(154)$ & $53,672(340)$ \\
Health care & $15,400(98)$ & $22,679(144)$ \\
Cooking fuel & $5272(33)$ & $6766(43)$ \\
Educational expenses & $84,800(537)$ & $133,723(846)$ \\
Durable goods & $64,001(405)$ & $22,855(145)$ \\
Community welfare & $11,800(75)$ & $22,332(141)$ \\
Transportation & $12,000(76)$ & $14,879(94)$ \\
Utilities & $10,026(64)$ & $12,214(77)$ \\
Non-food expenditure & $256,000(1620)$ & $731,710(4631)$ \\
Total expenditure & $553,725(3505)$ & $999,078(6323)$ \\
DM costs as a proportion of non-food expenditure & $20.4 \%$ & $11 \%$ \\
Catastrophic DM cost & $45 \%$ & $88 \%$
\end{tabular}

\section{Discussions}

The economic burden and catastrophic expenditure among type2 PLWD in this study was found to be high. Worse still, for the lowest SES (q1). All SES groups had high catastrophic cost but the poorest are worse off. The mean monthly direct cost of N56,245 (US\$ 356) per PLWD is considered so high for respondents' mean non-food consumption expenditure of N256,000 (US\$1620).

DM cost is more than twice non-consumption expenditure of q1 N24,617 (US\$ 156) and more than $43 \%$ that of q4 N120,228 (US\$ 761). DM cost in this study appears higher than in previous studies with (US \$ 197) per annum in outpatient study in Karachi Pakistan in 2007 
Table 5 Respondents' expenditure per month by socioeconomic status, catastrophic expenditure and the monthly mean cost of treating DM at the centre in $N(U S \$)$

\begin{tabular}{|c|c|c|c|c|}
\hline Expenditure & Q1 the poorest $n=74$ & Q2 the poorer poor $n=73$ & Q3 the poor $n=73$ & Q4 the least poor $n=72$ \\
\hline Non-food expenditure & $24,616(156)$ & $43,166(273)$ & $67,991(430)$ & $120,228(761)$ \\
\hline Ratio of non-food (qn/q1) & 1 & 1.75 & 2.76 & 4.88 \\
\hline Ratio qn/q4 & 0.20 & 0.36 & 0.57 & 1 \\
\hline \multicolumn{5}{|l|}{ Catastrophic threshold } \\
\hline Threshold of 40 catastrophic & $42(57 \%)$ & $20(27 \%)$ & $13(18 \%)$ & $12(17 \%)$ \\
\hline Threshold of 30 catastrophic & $58(78 \%)$ & $34(47 \%)$ & $38(52 \%)$ & $28(39 \%)$ \\
\hline Threshold of 10 catastrophic & $64(87 \%)$ & $56(78 \%)$ & $50(69 \%)$ & $25(35 \%)$ \\
\hline $\begin{array}{l}\text { Mean cost of treatment of DM at the } \\
\text { centre }\end{array}$ & $56,245(356)$ & $56,245(356)$ & $56,245(356)$ & $56,245(356)$ \\
\hline
\end{tabular}

[24] and \$ 2144.2 per PLWD per year in a West African region study in 2009; [25] but lower than N180,582 (US\$1143) in cost of DM foot ulcer [19] in Nigeria 2007.

Diet ranking is highest followed by drugs and investigations differed from previous studies where drugs ranked highest. This high cost may not be unrelated to increasing healthcare cost, high cost of diabetic supplies, frequent visit to hospitals, wide claims on DM diet for "cure", on media and streets by traditional healers, late reporting with complications and co-morbidities that are known to increase cost burden of DM $[18,22,26]$. High cost of care is likely to impede effective DM care due to low purchasing power, out of pocket payment at the point of need and absence of prepayment mechanisms [12]. Lack of access to effective DM could expose patients complications that will reduce the quality of life, increase morbidity, mortality and productivity loses which has far reaching implications for development. The only way to explain how they paid this huge direct cost is use of payment coping mechanisms; interim measures to meet up with health cost (social support, borrowing, sale of assets, cutting back on consumption of basic needs, skipping appointments or abandoning treatment when feeling well, instalment payment, etc. [12, 27, 28]. Unfortunately financing health care with payment mechanisms further inflates the total costs and push the patients deeper into 'hidden' poverty [28]. Catastrophic direct cost was $45 \%$ at $30 \%$ threshold implying that $45 \%$ of the 292 respondents, spent $30 \%$ and above of their non food consumption expenditure (income) on diabetic care.

The catastrophic DM expenditure at $30 \%$ threshold within the SES quartiles (q1-q4) of 58 (78 \%), 34 (47\%), 38 (52\%) and 28 (39\%), respectively is considered quite high especially for the poorest with meagre income but must buy at same rate with rich at the facility or forfeit treatment. Previous studies had described this catastrophic cost as financial expenditure that is crippling to household and disrupts their standards of living [29, 30].
Using fixed threshold could mask degree of financial catastrophe and the inequity in financial access to care between poorest and least poor [11, 15]. For example at $30 \%$ threshold in the present study, catastrophic cost was high among all the socioeconomic status groups. The remaining $70 \%$ of non-food expenditure would amount to $\mathrm{N17,232}$ (\$109) for the poorest and almost five times higher for the least poor, N84,160 (\$533). Thus the least poor cannot be said to be facing as great catastrophe as the poorer ones. The least poor could cut back on his luxuries to cope but the poorest is left with only N17,232 (\$109) to survive on. The use of variable threshold to measure catastrophe gave a higher overall and disaggregated levels of catastrophe which is considered a better measure reflecting the differences in purchasing power between the rich and the poor [11].

For example at a variable threshold of $10 \%$ for the poorest and $40 \%$ for the least poor, the catastrophic costs were $64(87 \%)$ and $12(17 \%)$, respectively. At the expenditure of $10 \%$ non food more than $80 \%$ experienced financial distress while the least poor will spend almost five times of the same and only $17 \%$ will experience catastrophe. The richest quartile would need to spend about $40 \%$ of their non-food consumption on DM before having the risk of being tipped into poverty while the poorest quartile would need to spend 1/10 that of the richest to be thrown into poverty. Measure of inequality is the ratio of q1/q4 non-food expenditure 1:4.9. Catastrophic cost in this study were higher than previous studies. Although there was no Nigerian Catastrophic DM cost study found in literature other cost of illness studies (TB, Malaria, etc.) in Nigeria demonstrated high catastrophic cost. Onoka and colleagues examined catastrophic health expenditure in Nigeria at variable and fixed thresholds; observed $14.8 \%$ catastrophe at $40 \%$ non-food expenditure with 22.6 and $7.6 \%$ of the poorest and richest, respectively. At a variable threshold of 5 and $29.6 \%$ for the poorest and the 
richest the catastrophic level were 44.7 and $12.0 \%$ [12]. However Ichoku and colleagues observed, 3-5 \% catastrophic spending at $10 \%$ threshold [10]. In a household survey of catastrophic health expenditure in South east Nigeria $(\mathrm{n}=167)$ highest proportion was noted among the poorest [31]. At a variable threshold of 5 and $29.6 \%$, (q1 and q4) catastrophic level were 44.7 and $12 \%$, respectively [31].

As revealed in studies $(11,12,13)$ it was not somewhat a surprise to find catastrophic expenditure in a country that has the highest DM burden in Africa with no prepayment mechanism to pool financial risk, $>70 \%$ of the population live below $\$ 1$ per day, $>90 \%$ use private funding for health services and late reporting for care. However, it becomes a great concern considering that PLWD will need to contend with these costs throughout lifetime.

Secondly the magnitude of economic burden and catastrophic cost observed in this study in South east Nigeria is major concern because, the area is one of the oil producing states with better resource allocation and the National Health Insurance Scheme which presently covers some categories of government workers, is being implemented.

The disproportionate, experience of catastrophe tilting towards lower socioeconomic groups in the present study means that the poor is not protected from impact of out of pocket spending (OOPS) and increasing care cost (inequity) [32].

Urgent re-visitation of the current health financing strategy to provide for financial risk protection of the poor through policy decision making is needful to reduce economic burden of DM. Government should adopt financial strategies that rely less on private funding.

\section{Study limitations}

The study has some limitations. Due to the 1 month recall some cost items may be missed due to forgetfulness. Another limitation is that cost estimation may risk double counting because of cost of co-morbidity (costof-illness problem). Multiple accesses for care within the period of study may lead to loss of unit costs. Furthermore self-report of costs can give an underestimation or exaggeration of the problem. Asset based information was observed to be sensitive to some respondents. The study was confined to only one hospital in the state therefore findings cannot be generalized. There was no Nigerian patient-based cost of DM and catastrophic expenditure out-patient study cited as non was seen in literature review.

\section{Conclusions}

This study demonstrated a high economic burden of type 2 diabetes mellitus that led to catastrophic expenditure especially among the lowest socioeconomic status group. Consistent with previous studies, the results illustrate the difference in level of catastrophic spending. This calls for re-visitation of the present health financing policy to accommodate pro-poor policies that will make DM care free at the delivery point, subsidize costs or provide a wider coverage of National Health Insurance.

\section{Abbreviations}

\$: US dollar; N: Naira; AIDS: acquired immune deficiency syndrome; DM: diabetes mellitus; HIV: human immunodeficiency virus; OOPS: out of pocket spending; SES: socio-economic status; TB: tuberculosis; UN: United Nations; WHO: World Health Organisation.

\section{Authors' contributions}

OIL did the instrument validation and critically reviewed the manuscript, final review of the manuscript following editorial (peer reviewers') comments. EJN: conception of research problem, did the instrument development, participated in the data collection, the design of the study and manuscript drafting, final review of the manuscript following editorial (peer reviewers') comments OEU: assisted in instrument development, arranged data for analysis, helped in manuscript draft, final review of manuscript following editorial (peer reviewers') comments. OPU contributed in the data presentation and helped to draft the manuscript, line numbering of the manuscript and final review of manuscript. AFO assisted in research design, helped to draft the manuscript and contributed to funding. All authors read and approved the final manuscript.

\section{Author details}

${ }^{1}$ Department of Health Administration and Management, University of Nigeria Nsukka, Enugu Campus, Enugu, Enugu State, Nigeria. ${ }^{2}$ Federal Medical Centre Umuahia, Umuahia, Abia State, Nigeria. ${ }^{3}$ Department of Nursing, University of Nigeria Nsukka, Enugu Campus, Enugu, Enugu State, Nigeria. ${ }^{4}$ Department of Nursing, College of Health Sciences, Ladoke Akintola University of Technology, Osogbo, Osun State, Nigeria.

\section{Acknowledgements}

We acknowledge the guidance of Prof Obinna Onwujekwe in instrument development and face validation of same based on his wealth of knowledge in health economics and passion for equity in healthcare financing. We appreciate Dr. Uche Ekpemiro and Sopuruchi Ekpemiro their help in sourcing material for literature review, typesetting this work. We are grateful to Dr. and Dr. Mrs Caleb Ezeano for sourcing the Analyst that did the analysis of this work based on its peculiarities. We are thankful to Dr. Ikenna Okpala for sourcing the suitable journal for publication and arranging for same. We thank all the participants for their time and cooperation throughout the duration of the study. We are grateful to the management of the hospital for giving us approval to embark on this study.

\section{Compliance with ethical guidelines}

\section{Competing interests}

The authors declare that they have no competing interests.

Received: 5 December 2014 Accepted: 21 September 2015

Published online: 01 October 2015

\section{References}

1. Adebayo FF. New trends in the management of diabetes. Pharmanews. 2009:31:11.

2. Bilikis B. Reducing prevalence of diabetes mellitus. http://www.bussinessdayonline.com/NG/index.php/analysis/commentary/47930-reducingprevalence-of-diabetes-m. Accessed 23 Nov 2012

3. Kiriga JM, Barry SP. Health challenges in Africa and the way forward. Int Arch Med. 2008;1:27. 
4. Odeleye. Diabetes incidence on the rise. Pharmanews. 2008;30(6):22-4.

5. International Diabetes Federation. Prevalence of diabetes in African region. 2012. http://www.idf.org/. Accessed 6 Mar 2012

6. Smeltzer SC, Bare BG, Hinkle JC, Cheever HK. Brunner and Studdarths' Textbook of medical surgical nursing. 11th ed. Philadelphia: Lippincott, Williams and Wilkins; 2008

7. Sridhar D. Non communicable diseases are development concern. United Nations general assembly special session. January 2011. New York

8. World Health Organization. Designing health financing systems to reduce catastrophic health expenditure. Technical briefs for policy makers number 2. (WHO/EIP/HSF/PB/05.02) Geneva: WHO; 2005.

9. Ichoku HE, Eme H, Fonta WM, Onwujekwe OE. Incidence and intensity of catastrophic healthcare financing and impoverishment due to out-of-Pocket payments in Southeast Nigeria. J Insur Risk Manage. 2009;4(4):47-59.

10. Ichoku HE, Eme H, Fonta WM. Catastrophic healthcare financing and poverty; empirical evidence from Nigeria. J Soc Econ Develop. 2009;11(2):1-16

11. Onoka CA, Onwujekwe OE, Hanson K, Uzochukwu BS. Measuring catastrophic healthcare expenditure in Nigeria: implication for financial risk protection. CREHS Res Br. 2010;2:1-2. http://www.crenhs.ishtm.ac.uk/ downloads/pub.

12. Onoka CA, Hanson K, Onwujekwe O, Uzochukwu B. Examining catastrophic health expenditures at variable thresholds using household consumption expenditure dairies. Trop Med Int Health. 2011;16(10):1334-41.

13. Soyibo A, Olaniyan O, Akanni OL. National health account of Nigeria: 2003-2005, incorporating sub national health accounts of states. Report submitted to the Federal Ministry of Health Abuja, 2009

14. Carrin G, Evans D, Xu K. Designing health financing policy towards Universal coverage. Bull World Health Organ. 2007;85(9):652.

15. International Diabetes Federation. Global guideline for management of type2 diabetes. 2005. http://www.idf.org/.

16. Zhang PZX, Brown JB, Vistisen D, Sicree RA, Shaw J, Nichols GA. Economic impact of diabetes. 2010. Retrieved from www.idf.org/sites/default/fles/ eco. Accessed 10 Aug 2011.

17. United Nations General Assembly resolution 66/2, 2011. http://www.who. int/nmh/events/un_ncd_summit2011/political_declaration_en.pdf.

18. Azevedo M, Allai S. Diabetes in Sub-Saharan Africa: Kenya, Mali, Zambia, Nigeria, Mozambique and South Africa. Int J Diabetes Dev Ctries. 2008;28(4):101-8. doi:10.4103/0973-3930.45268.

19. Ogbera AO, Fasanmade O, Ohwovoriole AE, Adediran O. An assessment of the disease burden of foot ulcer in patients with diabetes mellitus attending a teaching hospital in Lagos, Nigeria. Int J Lower Extremity Wounds. 2007;5:244-9.

20. Idemyor V. Diabetes in Sub-Saharan Africa: healthcare perspectives, challenges and the economic burden of disease. J Natl Med Assoc. 2010;102:650-3.
21. Onwujekwe OE. Inequities in healthcare seeking in the treatment of communicable endemic diseases in Southeast Nigeria. Soc Sci Med 2005;61(2):455-63. doi:10.1016/j.socscimed.2004.11.066.

22. Songer TJ, Ettaro L, Economics of Diabetes Project Panel: Studies on the cost of diabetes. Center for Disease Control. National Center for Chronic Disease Prevention and Health Promotion, Division of Diabetes Translation, Atlanta; 1998.

23. National Bureau of Statistics. The Nigerian statistical fact sheet in economic and social development. 2007.

24. Liaquat K, Khuwaja A, Cosgrove P. Cost of diabetes care in outpatient clinic of Karachi, Pakistan. BMC Health Serv Res. 2007;7:189. doi:10.1186/1472-6963-7-189.

25. Kiriga JM, Sambo HB, Sambo LG, Barry SP. Economic burden of diabetes in the West African region. BMC Int Health Hum Rights. 2009;9:6. doi:10.1186/1472-698X-9-6.

26. Idris J. Taming hypertension and diabetes in Nigeria. Pharmanews. 2009 31(9).

27. Russel S. Economic burden of illness for household in developing countries focussing on Malaria, TB and HIV/AIDS. Am J Trop Hyg. 2004;71(suppl2):147-55.

28. Oyakale TO, Yusuf SA. Multi-dimensional poverty of shock-exposed households and coping mechanism in rural Nigeria. Soc Sci. 2010;5:254-63.

29. Mudur G. Catastrophic personal payment in 381 Asia. BMJ. 2007. doi:10.1136/bmj.39139.656678.DB.

30. Doorslaer EV, Donnel OO, Rannan-Eliya RP, Somanathan A, Adhikari SR Garg CC, Harbianto D, Herrin AN, Huq MN, Ibragimova S, et al. Catastrophic expenditure on healthcare: comparative evidence from Asia. Health Econ. 2007;16:1159-84.

31. Onwujekwe OE, Hanson K, Uzochukwu BS. Examining inequities in incidence of catastrophic experience of different health services and health facilities in Nigeria. PLoS One. 2012. doi:10.1371/journal.pome.0040811.

32. Onwujekwe OE, Hanson K, Fox-Rushby J. Inequalities in acquisition of mosquito nets and willingness to pay for insecticide treated nets in Nigeria: threats to successes of malaria control interventions. Malaria J. 2004;3:6. doi:10.1186/1475-2875-3-6.20.

\section{Submit your next manuscript to BioMed Central and take full advantage of:}

- Convenient online submission

- Thorough peer review

- No space constraints or color figure charges

- Immediate publication on acceptance

- Inclusion in PubMed, CAS, Scopus and Google Scholar

- Research which is freely available for redistribution

Submit your manuscript at 